\title{
SYNTHESIS ASSISTED BY MICROWAVE OF ZnO/ZnS/CuS HETEROSTRUCTURES AND ITS PHOTOACTIVITY USING VISIBLE LIGHT FOR DYES DEGRADATION
}

\author{
IzQuierdo de la CRuZ, F. ${ }^{1}$ - PÉREZ HeRnándeZ, G. ${ }^{1}$ - RodrígueZ Melgarejo, F. $^{2}$ - Ruiz \\ Peralta, M. L. ${ }^{3}$ - CASTillo Palomera, R. ${ }^{4}-$ RAMírez Morales, E. ${ }^{1}-$ Rojas BlanCo, L. ${ }^{*}$ \\ ${ }^{1}$ Universidad Juárez Autónoma de Tabasco, Avenida Universidad S/N, Col. Magisterial, C.P \\ 86040, Villahermosa, Tabasco, México \\ ${ }^{2}$ Cinvestav, Libramiento Norponiente \#2000, Fracc. Real de Juriquilla, C.P. 76230, Santiago \\ de Querétaro, Qro., México \\ ${ }^{3}$ Benemérita Universidad Autónoma de Puebla, Facultad de Ingeniería Química, Av. San \\ Claudio y 18 Sur, C.P. 72570 Puebla, Puebla, México \\ ${ }^{4}$ Universidad Politécnica de Chiapas, Carr. Tuxtla-Villaflores K.M. 1+500, Las Brisas, C.P. \\ 29150, Suchiapa, Chiapas, Mexico \\ *Corresponding author \\ e-mail: lizethrb@gmail.com; phone: +52-993-246-8500; fax:+52-914-336-0940
}

(Received 28 $8^{\text {th }}$ Jun 2018; accepted $14^{\text {th }}$ Aug 2018)

\begin{abstract}
In this study $\mathrm{ZnO} / \mathrm{ZnS} / \mathrm{CuS}$ heterostructure have been controllably synthesized through a microwave-assisted synthesis and cation exchange. The compounds $\mathrm{ZnO}, \mathrm{ZnO} / \mathrm{ZnS}$ and $\mathrm{ZnO} / \mathrm{ZnS} / \mathrm{CuS}$ were characterized by X-ray diffraction (XRD), scanning electron microscopy (SEM), ultravioletvisible (UV-vis) and Raman. It is found that the crystal structures obtained were Hexagonal Wurtzita for $\mathrm{ZnO}$, hexagonal Wurtzita for $\mathrm{ZnS}$, and hexagonal covellina for CuS. In comparison of $\mathrm{ZnO}$ and $\mathrm{ZnO} / \mathrm{ZnS}$ the results show that $\mathrm{ZnO} / \mathrm{ZnS} / \mathrm{CuS}$ heterostructure has a higher photocatalytic activity under visible light, because its photocatalytic properties increase, helping to separate the electron-hole. These $\mathrm{ZnO} / \mathrm{ZnS} / \mathrm{CuS}$ efficiently decompose organic dyes such as methyl orange and methylene blue upon visible light conditions. Degradation rates can reach $31 \%$ and $71 \%$ during 240 min of treatment, respectively. The experiments revealed that the $\mathrm{ZnO} / \mathrm{ZnS} / \mathrm{CuS}$ decomposes methylene blue much faster than methyl orange.
\end{abstract}

Keywords: semiconductors, photocatalysis, water treatment, $\mathrm{KOH}$, pollutant

\section{Introduction}

In recent years, environmental problems have generated a greater concern for society, due to the excessive growth that companies have presented, which means an increase in the number of pollutants they are producing. An exhaustive research of new techniques has been developed for water treatment; that they are no only low cost, but friendly to the planet (Chaudhuri, 2017). In the search for these new techniques, photocatalysis plays a fundamental role mainly due to its different applications, such as environmental remediation (Ahmad et al., 2016) and hydrogen production (Okemoto et al., 2018).

Of the photocatalysts most widely used, it includes $\mathrm{TiO}_{2}$ ( $\mathrm{Liu}$ and $\mathrm{Li}, 2014$ ), $\mathrm{ZnO}$ (Liu et al., 2015) and ZnS (Wan et al., 2014). The semiconductor materials, either type $\mathrm{p}$ or n-type (Zhang and Jaroniec, 2018), play a fundamental role due to their different properties such as the great potential as a photocatalyst, its low cost, high 
surface area and low toxicity (Park, Kim, et al., Photoinduced charge transfer processes in solar, photocatalysis based on modified $\mathrm{TiO}_{2}$ 2016), because the energy gap is small, An electron can be excited from the valence band to the conduction band, and then an electron-hole pair is generate producing oxidation-reduction reactions, taking advantage of the photocatalytic efficiency of these semiconductor materials.

The $\mathrm{ZnO}$ is a wide band gap semiconductor material, with a large surface area, photosensitivity, a high exciton binding energy of $(60 \mathrm{mV})$, and a band gap of $3.37 \mathrm{eV}$ that belong to II-VI group. $\mathrm{ZnO}$ is an important photocatalyst due to the rapidity to produce electron-hole pairs, but it has an important disadvantage as a photocatalyst, since it only can be activated in UV light $\lambda<385 \mathrm{~nm}$, therefore, several attempts have been made to improve the absorption capacity of the structures based on $\mathrm{ZnO}$.

To improve the photocatalytic performance of $\mathrm{ZnO}$ and to be able to accept visible light, heterostructure are fabricated with other semiconductor material for enhanced their photocatalytic activity (Basu et al., 2014) and its advantage is based on the fact that each of its compounds plays an individual role in the absorption of photons (Zhu et al., 2008).

$\mathrm{ZnS}$ with a wide band gap is another well-known photocatalytic, that has a band gap of $3.72 \mathrm{eV}$ belongs to II-VI group semiconductor. However, as the $\mathrm{ZnO}$ is restricted to the ultraviolet range. To extend the photoresponse of $\mathrm{ZnO} / \mathrm{ZnS}$ ( $\mathrm{Li}$ et al., 2014). It has been shown that there is an efficient coupling between the $\mathrm{ZnS}$ and the $\mathrm{CuS}$. Cus is capable of activating zinc oxide and zinc sulphide in the visible region, thus improving the separation of electron-hole pairs (Paria and Reiser, 2014).

Thus, in this study the $\mathrm{ZnO} / \mathrm{ZnS} / \mathrm{CuS}$ was synthesized by microwaves, expanding the light absorption range and $\mathrm{ZnO} / \mathrm{ZnS} / \mathrm{CuS}$ can absorb photons from the range of the solar spectrum taking advantage of the main source of renewable energy that counts (sunlight).

\section{Materials and methods}

\section{Materials}

Zinc di-hydrated acetate $\left(\mathrm{Zn}\left(\mathrm{O}_{2} \mathrm{CCH}_{3}\right) 2\left(\mathrm{H}_{2} \mathrm{O}\right)\right.$, $100 \%$, J. T. Baker), potassium hydroxide (KOH, 85\%, CIVEQ), thioacetamide $\left(\mathrm{C}_{2} \mathrm{H}_{5} \mathrm{NS}, 99 \%\right)$ and cupric nitrate $\left(\mathrm{Cu}\left(\mathrm{NO}_{3}\right)_{2} \cdot 2.5 \mathrm{H}_{2} \mathrm{O}\right), 98 \%$, CIVEQ). The solutions were prepared with deionized water and ethanol ( $\mathrm{C} 2 \mathrm{H} 6 \mathrm{O}, 99.5 \%$, Meyer). For the evaluation of the photocatalytic activity, methyl orange $\left(\mathrm{C}_{14} \mathrm{H}_{14} \mathrm{~N}_{3} \mathrm{NaO}_{3} \mathrm{~S}\right.$, Meyer $)$ and methylene blue $\left(\mathrm{C}_{16} \mathrm{H}_{18} \mathrm{C}_{1} \mathrm{~N}_{3} \mathrm{~S}, \mathrm{CIVEQ}\right)$ were used.

\section{Synthesis of $\mathrm{ZnO}$}

In a typical synthesis $4.4506 \mathrm{~g}$ of $\mathrm{Zn}\left(\mathrm{O}_{2} \mathrm{CCH}_{3}\right) 2\left(\mathrm{H}_{2} \mathrm{O}\right)$ and $720 \mu \mathrm{L}$ of deionized water was dissolved in $50 \mathrm{~mL}$ of ethanol, the solution was under constant stirring at 30 RPM. After $5 \mathrm{~min}$ of stirring the $\mathrm{pH}$ was modified with potassium hydroxide $(\mathrm{KOH})$ to $\mathrm{pH}$. The mixture was then transferred to a vial which was sealed and heated to $130{ }^{\circ} \mathrm{C}$ by microwave irradiation for $15 \mathrm{~min}$. After cool down the mixture was filtered and washed with deionized water and acetone at least three times, in order to eliminate residual precursors, finally was dried for $24 \mathrm{~h}$ at $80{ }^{\circ} \mathrm{C}$ in an electric hot air oven. 


$$
-5747 \text { - }
$$

\section{Synthesis of $\mathrm{ZnO} / \mathrm{ZnS}$}

$0.050 \mathrm{~g}$ of $\mathrm{ZnO}$ previously synthesized, and $0.041 \mathrm{~g}$ of thioacetamide $\mathrm{C}_{2} \mathrm{H}_{5} \mathrm{NS}$ was dissolve in $40 \mathrm{~mL}$ of deionized water. The solution was stirred with an ultrasonic bath for $20 \mathrm{~min}$, then the solution was transferred to a vial which was sealed and irradiated with microwaves for $30 \mathrm{~min}$ at $650 \mathrm{~W}$. After cool down the mixture was washed with deionized water and acetone for three times, and finally dried in an electric hot air oven for $24 \mathrm{~h}$ at $90{ }^{\circ} \mathrm{C}$.

\section{Fabrication of $\mathrm{ZnO} / \mathrm{ZnS} / \mathrm{CuS}$}

The synthesis method of the $\mathrm{ZnO} / \mathrm{ZnS} / \mathrm{CuS}$ heterostructure was similar to that reported by $\mathrm{Can} \mathrm{Lu}(\mathrm{Lu}$ and Otros, 2016). $\mathrm{ZnO} / \mathrm{ZnS} / \mathrm{CuS}$ was synthesized by cation exchange. $0.0139 \mathrm{~g}$ of $\mathrm{ZnO} / \mathrm{ZnS}$ and $0.0317 \mathrm{~g}$ of copper nitrate $\mathrm{Cu}\left(\mathrm{NO}_{3}\right)_{2} \cdot 2.5 \mathrm{H}_{2} \mathrm{O}$ was dissolve in $20 \mathrm{ml}$ of deionized water. The solution was kept under constant stirring in an ultrasonic bath, at $80^{\circ} \mathrm{C}$ during $4 \mathrm{~h}$. The precipitate obtained was washed and dried for $24 \mathrm{~h}$ in an electric hot air oven and then pulverized.

\section{Characterization}

In order to know the crystal structure and its phases, the powders were studied using a Rigaku diffractometer (XRD), with $\mathrm{Cu}-\mathrm{K} \alpha$ radiation $(\lambda=1.544 \AA)$ over the range of $2 \theta$ between $20^{\circ}$ and $80^{\circ}$. The average crystallite size was calculated using the Scherrer equation (Eq. 1), which is described below;

$$
\beta=\frac{k \times \lambda}{B \times \cos \theta}
$$

where, $\lambda$ is the wavelength, $k$ is a constant (shape factor of the diffraction peak), $\beta$ is the average crystal size, $\theta$ is the peak position and $\mathrm{B}$ is the full width at half maximium intensity (Patterson, 1939).

The Surface morphology of powders was characterized by using a scanning electron microscopy (SEM) JEOL microscope model JSM-7100F with $10 \mathrm{kV}$ acceleration voltage and a working distance $\mathrm{WD}$. of $9.8 \mathrm{~mm}$. The powders of $\mathrm{ZnO}, \mathrm{ZnO} / \mathrm{ZnS}$ and $\mathrm{ZnO} / \mathrm{ZnS} / \mathrm{CuS}$ were adhered to a double-sided carbon tape for the correct taking of micrographs at magnifications of 1500x, 20,000x, 25,000x, 50,000x and 100,000x.

The optical properties were obtained using UV-Visible spectrophotometer SHIMADZU model UV-2600, with a R-928 photomultiplier over the range of 185 to $900 \mathrm{~nm}$. The band gap was calculated by the modified function of Kubelka-Munk $(\mathrm{F}(\mathrm{R}) * \mathrm{hv}) 1 / 2$, and the calculation of $\mathrm{F}(\mathrm{R})(E q .2)$.

$$
F(R)=\frac{1-R^{2}}{R \times 2}
$$

where $R$ is the diffuse reflectance and $F(R)$ is the absorbance (Choudhury, 2013).

Raman spectra of the samples were recorded with a HORIBA sciencific spectrophotometer model XploRA PLUS in a spectral range of 100 to $800 \mathrm{~cm}^{-1}$ with a $532 \mathrm{~nm}$ laser. 


$$
-5748-
$$

\section{Photocatalytic test}

The photocatalytic activity of $\mathrm{ZnO}, \mathrm{ZnO} / \mathrm{ZnS}$ and $\mathrm{ZnO} / \mathrm{ZnS} / \mathrm{CuS}$ were evaluated using Methyl Orange $(10 \mathrm{mg} / \mathrm{l})$ and Methylene Blue $(10 \mathrm{mg} / \mathrm{l})$ as an organic pollutant using a Halogen FTK lamp $120 \mathrm{~V}$, model 54875 placed at $10 \mathrm{~cm}$.

$0.0249 \mathrm{~g}$ of photocatalyst was added in $60 \mathrm{ml}$ of the dye, and kept in an ultrasonic bath in the dark to establish the absorption-desorption equilibrium. After $30 \mathrm{~min}$, an aliquot were removed and centrifuged at 4000 RPM for 25 min to separate the powders from the solution. The irradiation of visible light was started with the remaining dye in constant agitation at $180 \mathrm{RPM}$, at $28{ }^{\circ} \mathrm{C}$. Aliquots were taken every $30 \mathrm{~min}$ and centrifuged with the same conditions mentioned above. The degradation was monitored by UV-Vis absorption spectroscopy in the range of 340-600 $\mathrm{nm}$ for Methyl Orange, and $500-750 \mathrm{~nm}$ for Methylene Blue. The measurements were made during $240 \mathrm{~min}$. The degradation efficiency of the dyes was calculated with the degradation efficiency equation (Eq. 3).

Degradation efficiency

$$
E D(\%)=\frac{A_{0}-A_{\mathrm{t}}}{A_{0}} \times 100
$$

where $A_{0}$ is the initial absorbance of the dye and $A_{t}$ is the absorbance of the dye at a time $t$ (Alvi et al., 2017).

\section{Results and discussion}

The X-ray diffraction pattern was performed for the samples of $\mathrm{ZnO}, \mathrm{ZnO} / \mathrm{ZnS}$ and $\mathrm{ZnO} / \mathrm{ZnS} / \mathrm{CuS}$ (Fig. 1).

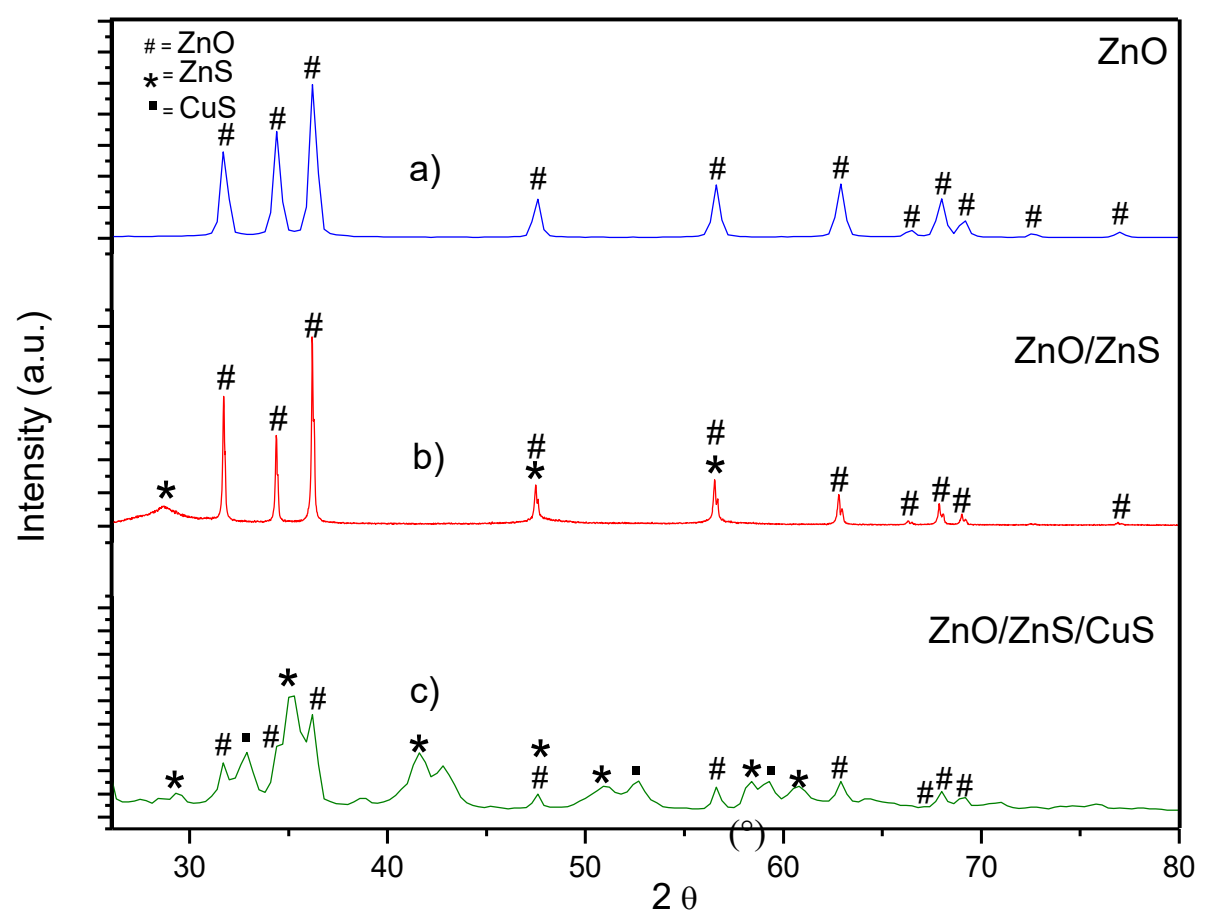

Figure 1. XRD patterns of the $\mathrm{ZnO}, \mathrm{ZnO} / \mathrm{ZnS}$ and $\mathrm{ZnO} / \mathrm{ZnS} / \mathrm{CuS}$ 


$$
-5749-
$$

The $\mathrm{ZnO}$ crystallizes in a hexagonal wurtzite phase (JCPDF 89-7102), and the average crystallite size is $21 \mathrm{~nm}$. The compound $\mathrm{ZnO} / \mathrm{ZnS}$ shows the characteristic peaks of both compounds $\mathrm{ZnO}$ and $\mathrm{ZnS}$; checking the obtaining of the hexagonal Wurtzite phase for $\mathrm{ZnO}$ (JCPDF 89-7102), and the appearance of zinc sulfide (JCPDF 72-0162) for the Wurtzita Hexagonal phase. Finally, the X-ray diffraction pattern of the heterostructure $\mathrm{ZnO} / \mathrm{ZnS} / \mathrm{CuS}$ is corrobored with the peaks of the coveline phase of CuS (JCPDS 741234).

The $\mathrm{ZnO}$ powders have an irregular morphology of semi-spherical shape and agglomerations, with particles ranging from 205 to $702 \mathrm{~nm}$ in diameter (Fig. 2), this morphology is characteristic of the materials prepared by the microwave-assisted method (Kajbafvala et al., 2012; Sooksaen and Chuankrerkkul, 2017).
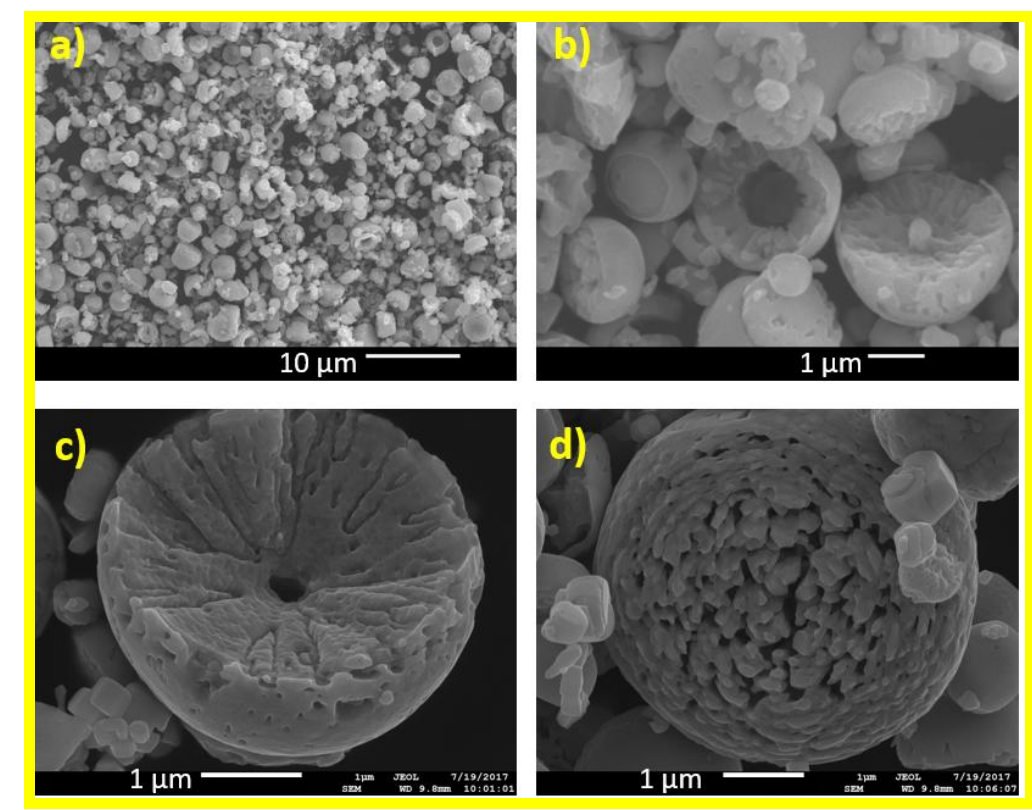

Figure 2. SEM images of $\mathrm{ZnO}$ a) $2500 x$ b) $15000 x$ c) $25000 x$ d) $20000 x$

The SEM images of $\mathrm{ZnO} / \mathrm{ZnS}$ after adding TAA and do not show variation with respect to the micrographs for $\mathrm{ZnO}$ (Fig. 3). Semi-spherical forms are presented with the formation of small spherical assembled particles, the size of these particles varies from 677 to $1400 \mathrm{~nm}$ in diameter.

Finally, the $\mathrm{ZnO} / \mathrm{ZnS} / \mathrm{CuS}$ heterostructure have a variation in the morphology with respect to the micrographs for $\mathrm{ZnO}$, and $\mathrm{ZnO} / \mathrm{ZnS}$ in which the circular morphology prevailed, varying for them to elongated forms with $380 \mathrm{~nm}$ in length (Fig. 4), which coincides with the morphology reported for this compound (Lu et al., 2016).

The optical absorbance was performed for the samples of $\mathrm{ZnO}, \mathrm{ZnO} / \mathrm{ZnS}$ and $\mathrm{ZnO} / \mathrm{ZnS} / \mathrm{CuS}$ (Fig. 5). The absorption Edge value of $\mathrm{ZnO}$ was obtained at $470 \mathrm{~nm}$ wich coinciding with the absorption edge values of the $\mathrm{ZnO}(3.37 \mathrm{eV})$. For $\mathrm{ZnO} / \mathrm{ZnS}$ is possible to observe two edges values of absorption which is associated with the electronic interaction between the $\mathrm{ZnO}$ and $\mathrm{ZnS}$ with the increase of $\mathrm{ZnS}$ in the surface of $\mathrm{ZnO}$ (Jia et al., 2013) however no significant changes of the absorption increase above $400 \mathrm{~nm}$ are observed. For the $\mathrm{ZnO} / \mathrm{ZnS} / \mathrm{CuS}$ the absorption edges of the heterostructure have been significantly improved allowing the absorption of light in the 


$$
-5750-
$$

visible region (400-800 nm), which implies that the sample has a good activity photocatalytic in visible light (Lu et al., 2016).

The band gap was calculated with the modified function of Kubelka-Munk $(\mathrm{F}(\mathrm{R}) * \mathrm{hv})$ $1 / 2$ as a function of the photon energy (hv), It shows the band gap value of the $\mathrm{ZnO}$ of $3.18 \mathrm{eV}$ which is similar to the value reported for the $\mathrm{ZnO}$ (Munirah et al., 2017). The band gap $3.17 \mathrm{eV}$ of the $\mathrm{ZnO} / \mathrm{ZnS} / \mathrm{CuS}$ is significantly decreased compared with to individual $\mathrm{ZnO}$, so that the increase of the surface of the $\mathrm{ZnS}$ over the $\mathrm{ZnO}$ produces a decrease in its band gap (Torabi and Staroverov, 2015), in the same way the value obtained from the band gap for the $\mathrm{ZnO} / \mathrm{ZnS} / \mathrm{CuS}$ is $3.09 \mathrm{eV}$ (Fig. 6).
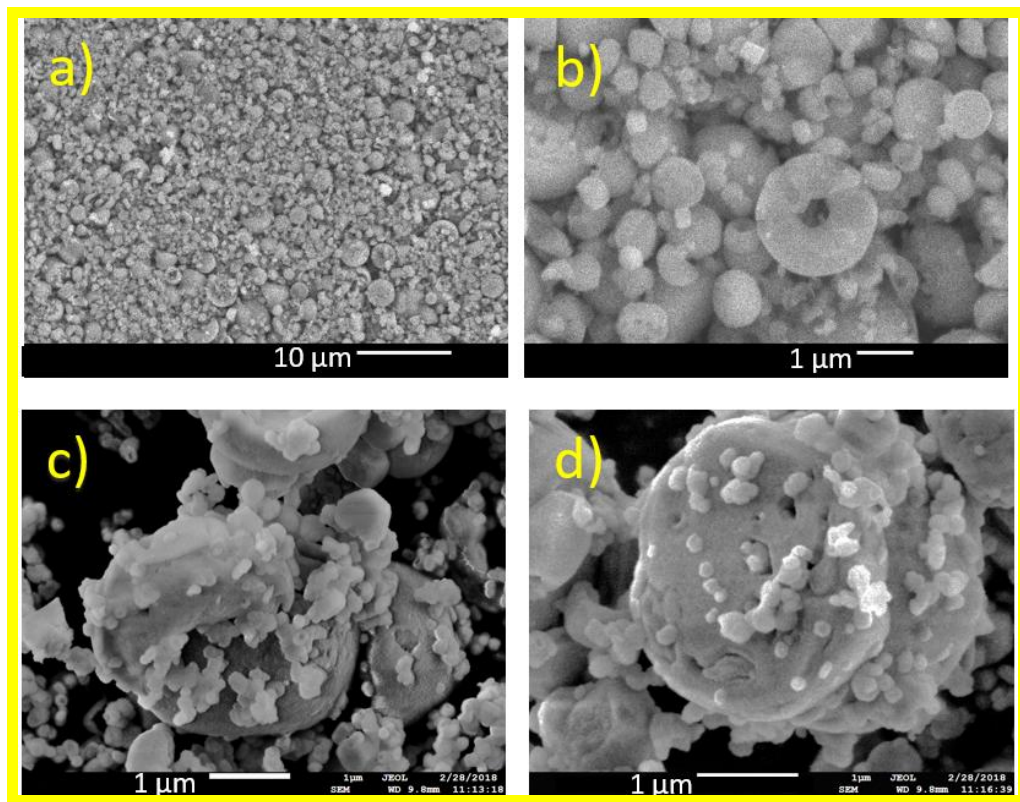

Figure 3. SEM images of $\mathrm{ZnO/ZnS} \mathrm{a)} 2500 x$ b) $15000 x$ c) $25000 x$ d) $20000 x$
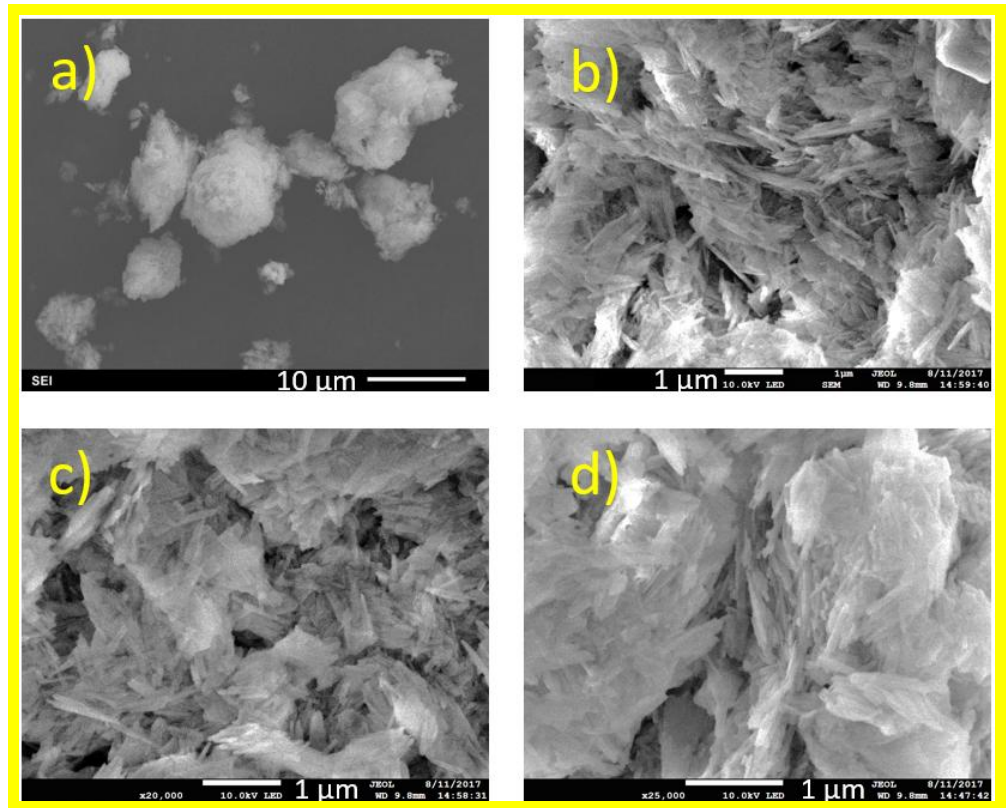

Figure 4. SEM images of ZnO/ZnS/CuS a) $2500 x$ b) $15000 x$ c) $25000 x$ d) $20000 x$ 


$$
-5751 \text { - }
$$

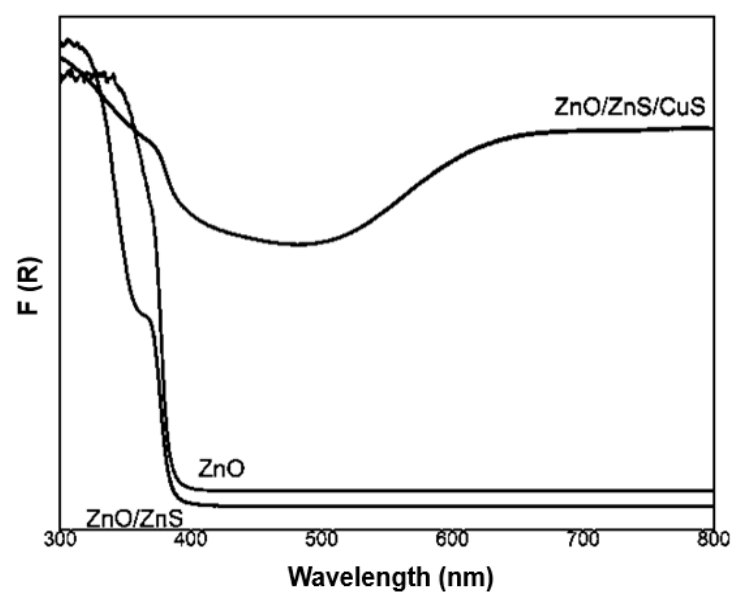

Figure 5. Plot of absorbance vs wavelength $\mathrm{ZnO}, \mathrm{ZnO} / \mathrm{ZnS}$ and $\mathrm{ZnO} / \mathrm{ZnS} / \mathrm{CuS}$

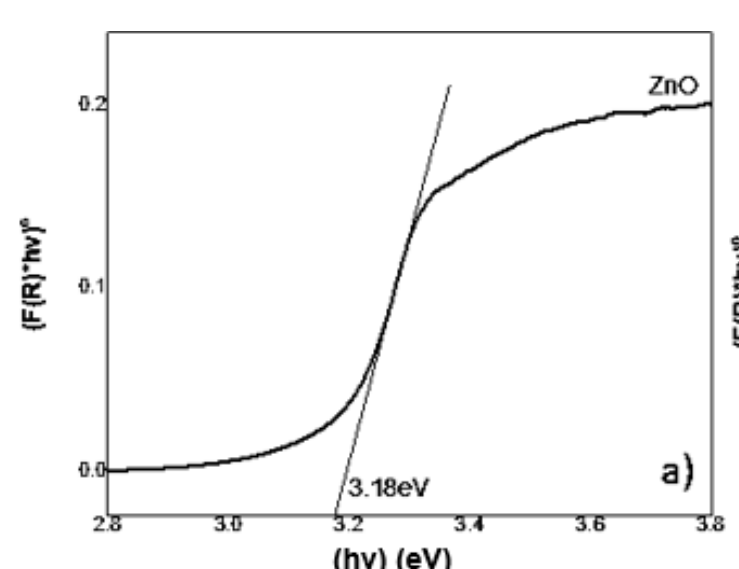

(hv) (eV)

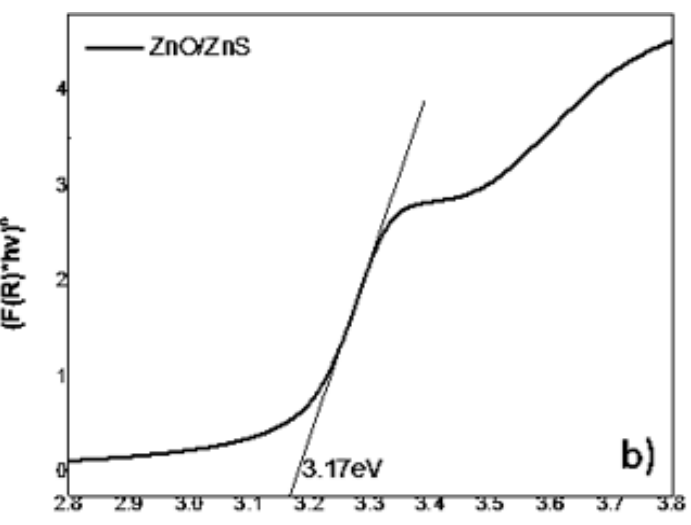

(hv) (eV)

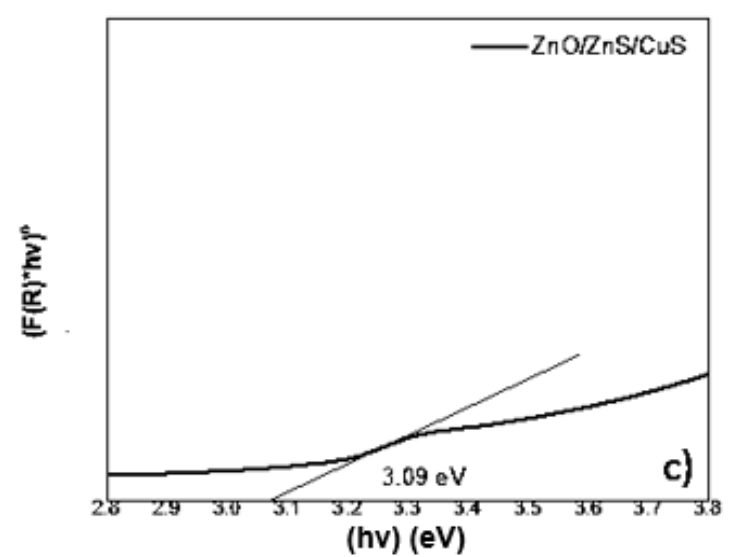

Figure 6. Band gap of a) $\mathrm{ZnO}$, b) $\mathrm{ZnO} / \mathrm{ZnS}$ and c) $\mathrm{ZnO} / \mathrm{ZnS} / \mathrm{CuS}$

To confirm the formation of the compounds, raman scattering analyzes were performed for the $\mathrm{ZnO}, \mathrm{ZnO} / \mathrm{ZnS}$ and $\mathrm{ZnO} / \mathrm{ZnS} / \mathrm{CuS}$ samples (Fig. 7). Zinc Oxide $\mathrm{ZnO}$, where the location of the vibrational modes located at $105,385,445,585$ and $663 \mathrm{~cm}^{-1}$ are associated with the vibrational active modes of the Wurtzite phase of $\mathrm{ZnO}$ (Ruiz et al., 2011) the dominant peak at $445 \mathrm{~cm}^{-1}$ is attributed to high-frequency phonons from 
oxygen atoms (Fletcher et al., 2014), and E1 (LO) mode at $585 \mathrm{~cm}^{-1}$ is associated with interstitial zinc and oxygen vacancies, the E2 2 peak at $105 \mathrm{~cm}^{-1}$ is associated with the vibrations of the zinc (Scepanovic et al., 2009), the vibrational mode E2 $2_{\text {high }}-\mathrm{E} 2_{\text {low }}$ at $337 \mathrm{~cm}^{-1}$ is associated with multifononic processes (Londoño-Calderón et al., 2012) and finally the vibrational mode $\mathrm{A}_{1} \mathrm{TO}$ at $385 \mathrm{~cm}^{-1}$ is associated with intrinsic defects (Sundara Venkatesh et al., 2016), for the $\mathrm{ZnS}$ the additional presence of two resonant raman lines is observed in 217 and $350 \mathrm{~cm}^{-1}$ that correspond to the active vibrational modes of the $\mathrm{ZnS}$, the spectrum shows the dominant peak in $350 \mathrm{~cm}^{-1}$ identified as a mode T2 (LO) of first order [20] (Milekhin et al., 2012), the LO mode in $217 \mathrm{~cm}^{-1}$ is attributed to the second order of raman scattering (Fairbrother et al., 2014). The heterostructure $\mathrm{ZnO} / \mathrm{ZnS} / \mathrm{CuS}$ locates the characteristic peaks that are associated with the presence of $\mathrm{ZnO}, \mathrm{ZnS}$ and $\mathrm{CuS}$ and the appearance of the new peak that denotes the presence of the coveline phase of $\mathrm{CuS}$ at $165 \mathrm{~cm}^{-1}$ and $465 \mathrm{~cm}^{-1}$ (Baert et al., 2013).

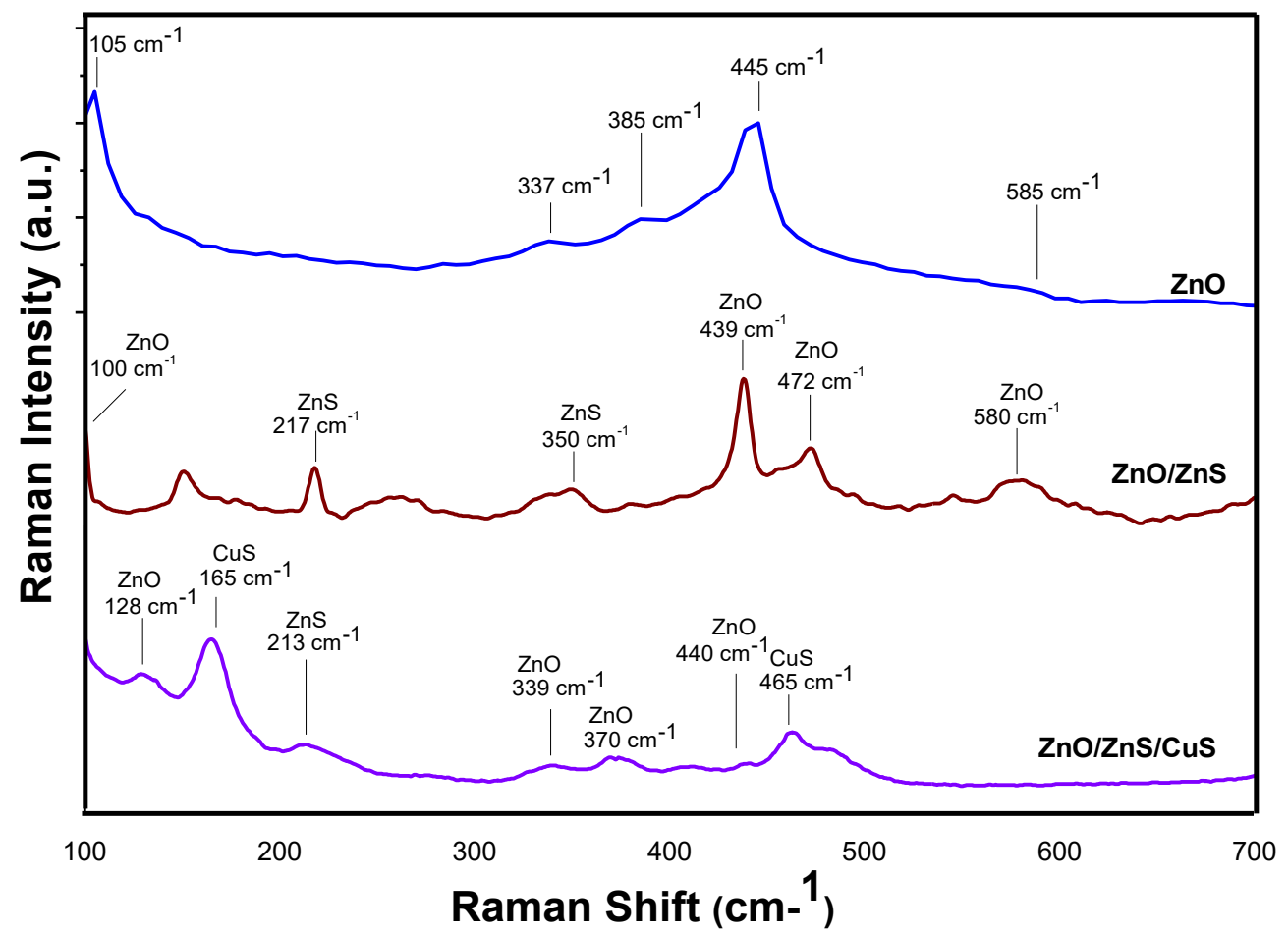

Figure 7. Raman spectra of $\mathrm{ZnO}, \mathrm{ZnO} / \mathrm{ZnS}$ and $\mathrm{ZnO} / \mathrm{ZnS} / \mathrm{CuS}$

The photocatalytic test was performed with the degradation of MB (methylene blue), and MO (methyl orange). The test was prepared with $0.0249 \mathrm{~g}$ of photocatalyst and a concentration of $10 \mathrm{ppm}$ of each of the dyes with the use of a lamp in the range of visible light. As mentioned in the methodology aliquots were taken every $30 \mathrm{~min}$ to measure its dye concentration during 240 min of reaction.

The UV-Vis absorption spectra show the degradation for the MB and MO dye with the time exposed to visible light radiation for $\mathrm{ZnO} / \mathrm{ZnS} / \mathrm{CuS}$ at a specific wavelength of $464 \mathrm{~nm}$ and $664 \mathrm{~nm}$ respectively (Fig. 8). As seem the aborbance intensity gradually decreased over time, according to what was reported by Lu et al. in 2016 this improvement can be attributed to the formation of the heterostructure constituted by the 


$$
-5753-
$$

three semiconductors $\mathrm{ZnO}, \mathrm{ZnS}$ and $\mathrm{CuS}$ with which it is possible to reduce the recombination of the electron-hole pair due to the difference of their band gap (Liu et al., 2014).
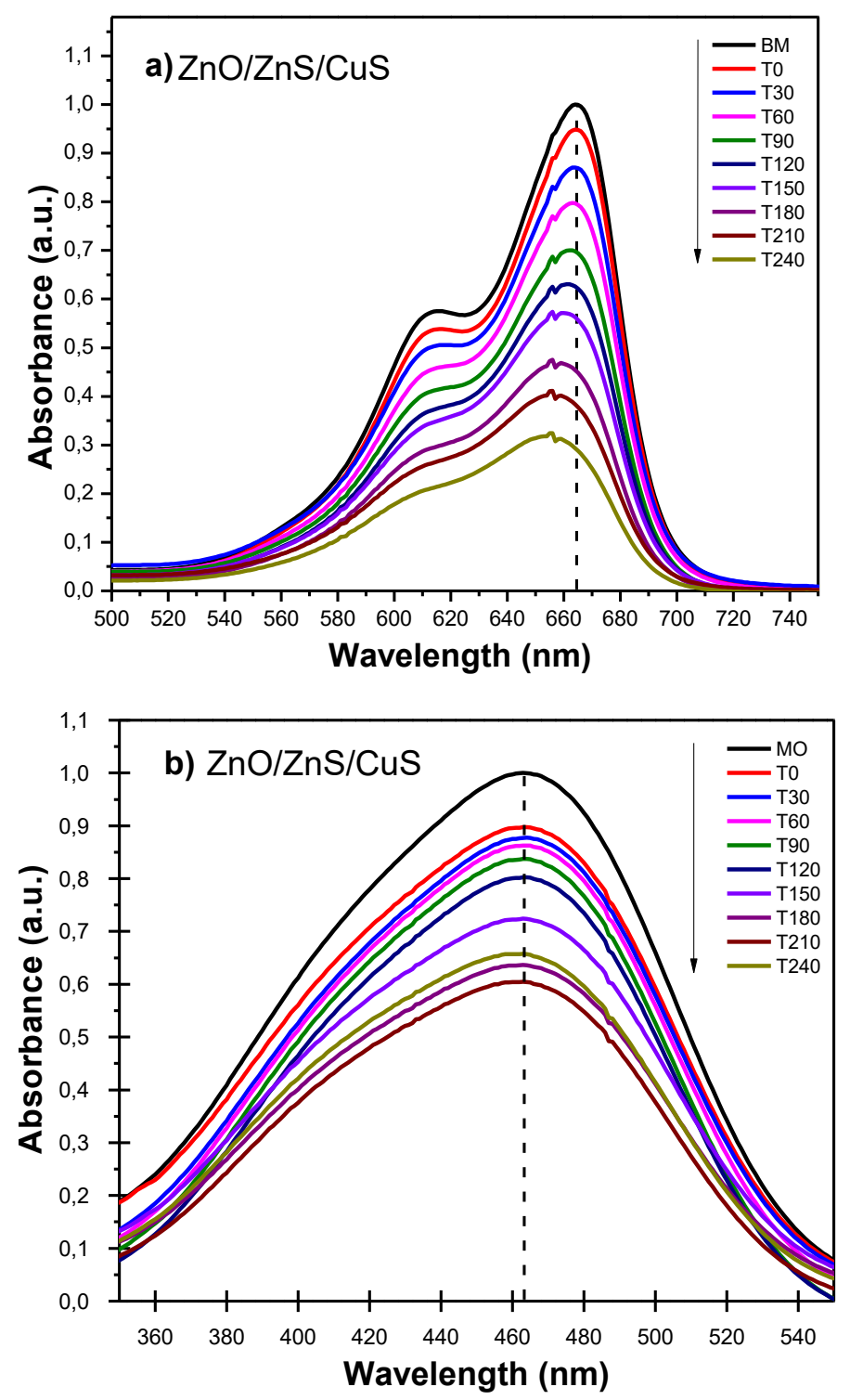

Figure 8. Photocatalytic decomposition of a) methylene blue and b) methyl orange

With the data obtained from the UV-Vis and applying the formula of the degradation efficiency ( $E q .3)$ to these values, it is established that the photocatalytic degradation of the $\mathrm{MB}$ increased by $\sim 57 \%$ of its efficiency for the pure $\mathrm{ZnO}$ at $\sim 61$ with $\mathrm{ZnO} / \mathrm{ZnS}$ and up to $\sim 71 \%$ for the $\mathrm{ZnO} / \mathrm{ZnS} / \mathrm{CuS}$ heterostructure under visible light irradiation during $240 \mathrm{~min}$ of reaction and the photocatalytic degradation efficiency of MO increased from $\sim 5 \%$ for $\mathrm{ZnO}$ to $\sim 16 \% \mathrm{ZnO} / \mathrm{ZnS}$ and up to $\sim 35 \%$ for $\mathrm{ZnO} / \mathrm{ZnS} / \mathrm{CuS}$ under the same conditions.

Figure 9 shows the values of the degradation of methyl orange and methylene blue in terms of $\mathrm{C} / \mathrm{C}_{0}$, where $\mathrm{C}$ is the concentration of $\mathrm{MB} / \mathrm{MO}$ at time $\mathrm{t}$ and $\mathrm{C}_{0}$ is the initial concentration of $\mathrm{MB} / \mathrm{MO}$. 


$$
-5754-
$$

All samples of heterostructures exhibit greater photocatalytic activity than pure $\mathrm{ZnO}$. The synthesized $\mathrm{ZnO} / \mathrm{ZnS} / \mathrm{CuS}$ showed high photocatalytic activity in methylene blue MB $(\sim 71 \%)$ unlike orange of methyl NM ( 35\%), this because the hydroxyl radicals play an important role in the breakdown of the anionic anionic dye orange methyl, while in cationic dyes such as methylene blue are involved in controlled reactions on the surface, resulting in the formation of intermediates that generally compete with the degradation of the original dye in solution ( $\mathrm{Li}$ et al., 2014) than $\mathrm{ZnO} / \mathrm{ZnS}$ and $\mathrm{ZnO}$ powders according to the exposure time (Fig. 9).

The difference of efficiencies in the degradation of contaminants is valid since each material is capable of degrading an organic compound efficiently or less efficiently due to the parameters that control the photocatalytic reactions such as temperature and $\mathrm{pH}$ (Scuderi et al., 2014).
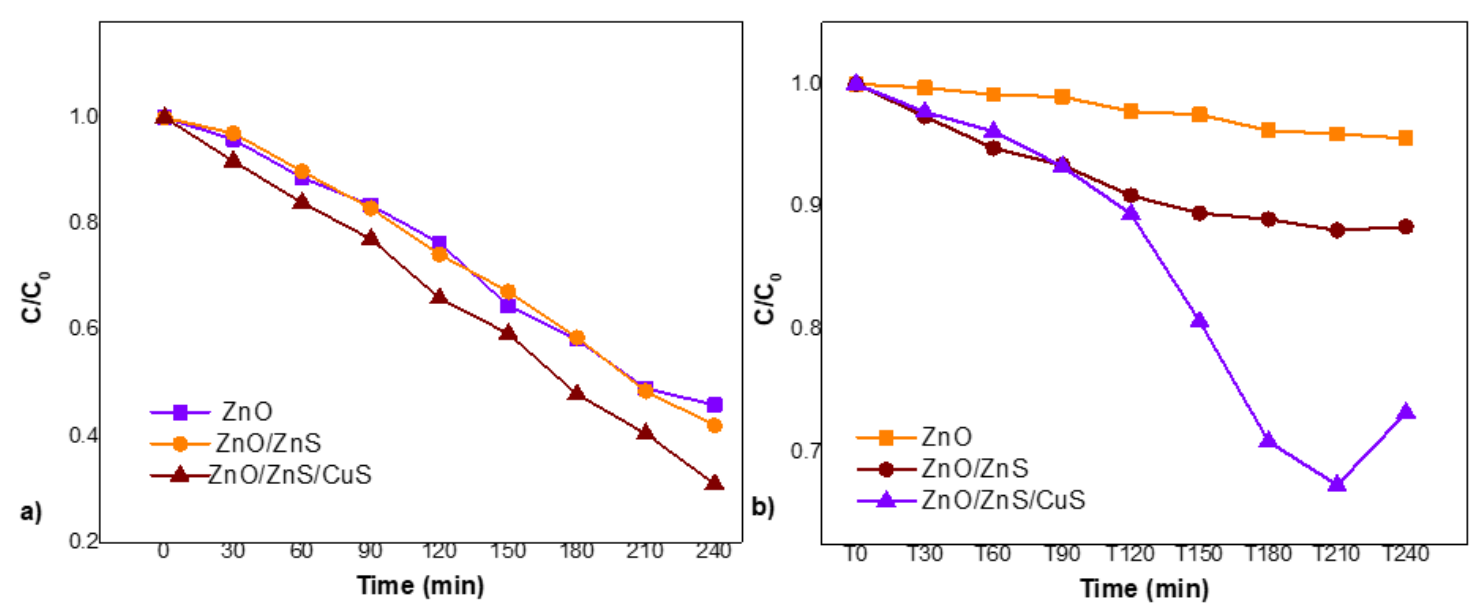

Figure 9. Photocatalytic decomposition of a) methylene blue and b) methyl orange

\section{Conclusions}

In this work, the $\mathrm{ZnO} / \mathrm{ZnS} / \mathrm{CuS}$ heterostructure was synthesized by microwaveassisted synthesis and cation exchange, which considerably modified its band gap. The $\mathrm{ZnO} / \mathrm{ZnS} / \mathrm{CuS}$ heterostructure can effectively decrease the recombination and exhibit a better photocatalytic activity in visible light compared to $\mathrm{ZnO}$ compared to the dyes analyzed in this study. We could also say that the heterostructure has a selective effect on the type and structure of the dye. It is recommended to modify the $\mathrm{pH}$ of the initial $\mathrm{ZnO}$ to improve the efficiency in the degradation, as well as to perform photocatalytic tests with mixed dyes.

Acknowledgements. The research group appreciates Edith Ponce Recinos for his support in the measures of SEM.

\section{REFERENCES}

[1] Ahmad, R., Ahmad, Z., Khan, A. U., Mastoi, N. R., Aslam, M., Kim, J. (2016): Photocatalytic systems as an advanced environmental remediation: Recent developments, limitations and new avenues for applications. - Journal of Environmental Chemical Engineering 4(4): 4143-4164. 
[2] Alvi, M. A., Al-Ghamdi, A. A., ShaheerAkhtar, M. (2017): Synthesis of ZnO nanostructures via low temperature solution process for photocatalytic degradation of rhodamine B dye. - Materials Letters 204: 12-15. DOI: 10.1016/j.matlet.2017.06.005

[3] Baert, K., Breugelmans, T., Buytaert, G., Van Brabant, J., Hubin, A. (2013): The combination of surface enhanced Raman spectroscopy and an ionic liquid as a model system to study the adhesion interface between sulfur and brass. - Journal of Raman Spectroscopy 44: 377-381.

[4] Basu, M., Garg, N., Ganguli, A. K. (2014): A type-II semiconductor ( $\mathrm{ZnO} / \mathrm{CuS}$ heterostructure) for visible light photocatalysis. - Journal of Materials Chemistry A 20: 7517-7525.

[5] Choudhury, B. (2013): Defect generation, d-d transition, and band gap reduction in Cudoped TiO2 nanoparticles. - International Nano Letters 3: 25.

[6] Fairbrother, A., Izquierdo-Roca, V., Fontané, X., Ibáñez, M., Cabot, A., Saucedo, E., Pérez-Rodríguez, A. (2014): ZnS grain size effects on near-resonant Raman scattering: optical non-destructive grain size estimation. - Cryst Eng Comm 16: 4121-4127.

[7] Fletcher, C., Jiang, Y., Sun, C., Amal, R. (2014): Morphological evolution and electronic alteration of $\mathrm{ZnO}$ nanomaterials induced by $\mathrm{Ni} / \mathrm{Fe}$ co-dopingt. - Nanoscale 6: 7312-7318.

[8] Jia, W., Jia, B., Qu, F., Wu, X. (2013): Towards a highly efficient simulated sunlight driven photocatalyst: a case of heterostructured $\mathrm{ZnO} / \mathrm{ZnS}$ hybrid structure. - Dalton Tras 42: 14178-14187.

[9] Kajbafvala, A., Ghorbani, H., Paravar, A., Samberg, J. P., Kajbafvala, E., Sadrnezhaad, S. K. (2012): Effects of morphology on photocatalytic performance of Zinc oxide nanostructures synthesized by rapid microwave irradiation methods. - Superlattices and Microstructures 51(4): 512-522.

[10] Li, J.-R., Wang, C.-C., Lv, X.-L., Zhang, Y.-Q. Guo, G. (2014): Photocatalytic organic pollutants degradation in metal-organic frameworks. - Energy Environ. Sci. 7(9): 28312867.

[11] Li, Y., Wang, X. Wang, M., Li, W., Chen, M., Zhao, Y. (2014): Synthesis of tunable $\mathrm{ZnS}-\mathrm{CuS}$ microspheres and visible-light photoactivity for rhodamine B. - New J. Chem. 38(9): 4182.

[12] Liu, C., Wang, Y., Meng, D., Yu, X., Wang, Y., Liu, J., Lu, C., Xu, K. (2014): Enhanced visible light photocatalytic performance of $\mathrm{ZnO} / \mathrm{ZnS} / \mathrm{CuS}$ ternary nanocomposites. Materials Letters 122: 197-200.

[13] Liu, C., Li, C., Fu, X., Raziq, F., Qua, Y., Jing, L. (2015): Synthesis of silicate-bridged $\mathrm{ZnO} / \mathrm{g}-\mathrm{C} 3 \mathrm{~N} 4$ nanocomposites as efficient photocatalysts and mechanism. - The Royal Society of Chemistry 5: 37275-37280.

[14] Liu, L., Li, Y. (2014): Understanding the reaction mechanism of photocatalytic reduction of C02 with H20 on Ti02-based photocatalysts: a review. - Aerosol and Air Quality Research 14: 453-469.

[15] Londoño-Calderón, M, Jurado, J. F., Vargas-Hernández, C. (2012): Estudio vibracional de nanoestructuras de $\mathrm{ZnO}$ sinterizadas por reacción en estado sólido. - Revista Colombiana de Física 44(1): 71-75.

[16] Lu, C., Liu, C., Chen, R., Fang, X., Xu, K., Meng, D. (2016): Synthesis and characterization of $\mathrm{ZnO} / \mathrm{ZnS} / \mathrm{CuS}$ ternary nanocomposites as high efficient photocatalyst in visible light. - Journal of Materials Science: Materials in Electronics 27:6947-6954. DOI: $10.1007 / \mathrm{s} 10854-016-4649-4$.

[17] Milekhin, A. G., Yeryukov, N. A., Sveshnikova, L. L., Duda, T. A., Himcinschi, C., Zenkevich, E. I., Zahn, D. R. T. (2012): Resonant Raman scattering of ZnS, ZnO, and $\mathrm{ZnS} / \mathrm{ZnO}$ core/shell quantum dots. - Appl Phys A 107: 275-278.

[18] Munirah, Z. R. K., Aziz, A., Khan, M. S., Khandaker, M. U. (2017): Influence of zinc concentration on band gap and sub-band gap absorption on $\mathrm{ZnO}$ nanocrystalline thin films sol-gel grown. - Materials Science-Poland 35(1): 246-253. 


$$
-5756-
$$

[19] Okemoto, A., Tanaka, K., Kudo, Y., Gohda, S., Koshiba, Y., Ishida, K., Horie, T., Taniya, K., Ichihashi, Y., Nishiyama, S. (2018): Hydrogen production for photocatalytic decomposition of water with urea as a reducing agent. - Catalysis Today 307: 231-236.

[20] Paria, S., Reiser, O. (2014): Copper in photocatalysis. - Chemcatchem Minireviews 6(9): 2477-2483.

[21] Park, H., Kim, H., Moonb, G. Choi, W. (2016): Photoinduced charge transfer processes in solar, photocatalysis based on modified TiO2. - Energy Environ. Sci. 9: 411-436.

[22] Patterson, A. L. (1939): The Scherrer formula for X-ray particle size determination. Physical Review 56: 978-982.

[23] Ruiz, P., de Lourdes, M., Serrano, J. G., Pal, U. (2011): Morphology defined ZnO nanostructures through microwave assisted chemical synthesis: growth mechanism, defect structure, and emission behaviours. - Advanced Science Letters 4: 1-8.

[24] Scepanovic, M, Grujic-Brojcin, K., Vojisavljevic, K., Bernik, S., Sreckovic, T. (2009): Raman study of structural disorder in ZnO. - Journal of Raman Spectroscopy 41: 914921.

[25] Scuderi, V., Impellizzeri, G., Romano, L., Scuderi, M., Nicotra, N., Bergum, K., Irrera, A., Svensson, B. G., Privitera, V. (2014): TiO2-coated nanostructures for dye photodegradation in water. - Nanoscale Research Letters 9(1): 458.

[26] Sooksaen, P., Chuankrerkkul, N. (2017): Morphology-design and semiconducting characteristics of zinc oxide nanostructures under microwave irradiation. - Integrated Ferroelectrics 177(1): 90-102.

[27] Sundara Venkatesh, P., Ramakrishnan, V., Jeganathan, K. (2016): Raman silent modes in vertically aligned undoped $\mathrm{ZnO}$ nanorods. - Physica B 481: 204-208.

[28] Torabi, A., Staroverov, V. N. (2015): Band gap reduction in $\mathrm{ZnO}$ and $\mathrm{ZnS}$ by creating layered $\mathrm{ZnO} / \mathrm{ZnS}$ heterostructures. - The Journal of Physical Chemistry Letters 6(11): 2075-2080.

[29] Wan, H., Xu, L., Huang, W.-Q. (2014): Band engineering of ZnS by codoping for visiblelight. - Appl Phys A 116: 741-750.

[30] Zhang, L., Jaroniec, M. (2018): Toward designing semiconductor-semiconductor heterojunctions for photocatalytic applications. - Applied Surface Science 430: 2-17.

[31] Zhu, Y. F., Fan, D. F., Shen, W. Z. (2008): a general chemical conversion route to synthesize various ZnO-based core/shell structures. - J. Phys. Chem. C 112: 1040210406. 